DEPARTMENT OF THE INTERIOR

U. S. GEOLOGICAL SURVEY

\title{
A SIX-CHANNEL SEISMIC AMPLIFIER
}

\author{
by \\ E. Gray Jensen ${ }^{1}$
}

Open-File Report 90-346

May, 1990

This report is preliminary and has not been reviewed for conformity with U.S. Geological Survey editorial standards. Any use of trade, firm or product names is for descriptive purposes only and does not imply endorsement by the U. S. Government.

1345 Middlefield Road, MS 977

Menlo Park, CA 94025 


\section{Table of Contents}

1. Introduction

2. Description

3. Table 1 (Parts list)

4. Table 2 (Jumper settings)

5. Figure 1 (Schematic)

6. Appendix A (PCB films)
5

$6 \& 7$

See below

Appendix A contains copies of photographic films and fabrication drawings used for production of the printed circuit board described herein. The duplicate films and drawings may be obtained for reproduction of the printed circuit board. They are available from the U. S. Geological Survey, Books and Open Files, Denver, CO 80225. 


\section{Introduction}

This report describes a basic six-channel instrumentation amplifier circuit board that the USGS has designed and used for amplification of seismic signals. It provides the circuit decription, schematic and the list of parts needed to construct it. Any interested person may borrow and duplicate the printed circuit board films (Appendix A) for making this amplifier. However, no warranty, expressed or implied, is made by the USGS as to the accuracy and functioning of the amplifier. Nor shall the fact of distribution constitute any such warranty, and no responsibility is assumed by the USGS in connection therewith.

\section{Description}

This circuit board was designed to be part of a system for amplifying, filtering and digitizing a large number of seismic channels. Each circuit board has six independant amplifier channels. Each channel has a gain setting which can be changed to $0,20,40,60$ or $80 \mathrm{~dB}$ by moving a jumper. It uses a monolithic integrated circuit instrumentation amplifier which can realize a noise figure (referred to input) of less than 1 microvolt peak-to-peak at high gain. The gain setting resistors used follow the recommendation of the manufacturer (Precision Monolithics Inc. Linear and Conversion Products 1986/1987 Data Book).

Refer to the parts list in Table 1 for an explanation of the part numbers used here. Also, see the circuit diagram in Figure 1. Solder terminals are mounted at Rx01, Rx02 and $\mathrm{Rx} 03$ to permit adding or changing damping resistors for use with seismometers. If no damping is desired, $\mathrm{Rx} 01$ and $\mathrm{Rx} 02$ can be shorted with wire. $\mathrm{Rx} 05$ and $\mathrm{Rx} 06$ provide input overvoltage protection in conjunction with diodes $\mathrm{CRx} 01$ and $\mathrm{CRx} 02$. They also work with $\mathrm{Cx} 01$ and $\mathrm{Cx} 02$ to filter high frequency noise out. It is very important that $\mathrm{Cx} 01$ and $\mathrm{Cx} 02$ be matched as closely as possible in capacitance (i.e. < 1\%) to maintain low noise. Rx04 and $\mathrm{Rx} 07$ provide a finite input impedance and stable operation with no input.

Resistors Rx08 through Rx11 set the amplifier gain from 0 to $60 \mathrm{~dB}$. With no jumpers installed $\mathrm{Rx} 11$ is connected yielding a gain of $1(0 \mathrm{~dB})$. Installing a jumper at JPx01 connects $\mathrm{Rx} 08$ in parallel with $\mathrm{Rx} 11$ for a gain of $10(20 \mathrm{~dB})$. Similarly, moving the jumper to JPx02 parallels Rx09 for a gain of $100(40 \mathrm{~dB})$ and JPx03 parallels Rx10 for a gain of 1000 (60 $\mathrm{dB})$. No more than one of these jumpers should be installed at a time. Rx12 sets the scale factor for 0 to $60 \mathrm{~dB}$. A jumper is normally installed at JPx04 to short Rx13. When a gain of $10,000(80 \mathrm{~dB})$ is needed, this jumper is removed adding Rx13 in series with Rx12. This should only be done when the $60 \mathrm{~dB}$ jumper (JPx03) is also installed. See Table 2 for proper jumper settings.

Potentiometer Rx14 is an input offset adjustment. It should be adjusted to produce zero volts output with the input shunted with a normal operating impedance. Capacitors C1, C2, $\mathrm{Cx} 03$ and $\mathrm{Cx} 04$ are power supply filtering devices. The board can be powered with $+/-5$ to $+/-18$ volts on pins 2 and 4 of the edge connector. Current consumption is typically 3 milliamps per side per amplifier channel. Additional information on specifications is available in the Precision Monolithics Data Book. 


\section{Table 1}

PARTS LIST

There are six identical amplifier circuits in this circuit board. The part numbers of all the components of a single amplifier circuit have the same number in the hundreds digit. That is amplifier channel 1 has part numbers in the 100's and channel number 6 has part number in the 600's. The corresponding parts of each amplifier have part numbers with the same value disregarding the hundreds digit. Therefore resistor R104 on channel 1 corresponds to R604 on channel 6. The letter " $x$ " in the following part numbers represents the hundreds digit of each of the six channels and can have a value of 1 to $6 ., \mathrm{C} 1$ and $\mathrm{C} 2$ are not associated with one particular channel and so do not have a hundreds digit. For each channel $\mathrm{Cx} 01$ and Cx02 must be selected to have capacitance as closely matched to each other as possible in order to maximize common mode rejection and minimize noise.

$\underline{\text { Part \# }}$

$\mathrm{C} 1, \mathrm{C} 2$

$\mathrm{Cx} 01, \mathrm{Cx} 02$

$\mathrm{Cx} 03, \mathrm{Cx} 04$

$\mathrm{CRx} 01, \mathrm{CRx} 02$

$\mathrm{Rx} 04, \mathrm{Rx} 07$
$\mathrm{Rx} 05, \mathrm{Rx} 06$
$\mathrm{Rx} 08$
$\mathrm{Rx} 09$

$\mathrm{Rx} 10$

$\mathrm{Rx} 11$

$\mathrm{Rx} 12$

$\mathrm{Rx} 13$

$\mathrm{Rx} 14$

Ux01

Misc.
Description

15 uf 20 VDC dipped tantalum

.22 uf Dip Ceramic X7R temp. (see text)

.01 uf Dip Ceramic

1N914

12

100 ohm

$1 / 4$ watt

$1 / 4$ watt

$1 / 8$ watt

$1 / 8$ watt

$1 / 8$ watt

$1 / 8$ watt

$1 / 8$ watt

$1 / 8$ watt

$90.9 \mathrm{~K}$

Bourns

32962-1-104 1001

$22.1 \mathrm{~K}$

$200 \mathrm{ohm}$

$200 \mathrm{~K}$

Bourns

PMI AMP-01-BX Instrumentation Amplifier

18-pin IC socket

6-pin inline jumper strips

2-pin inline jumper strips

Closed shorting jumper

$5 \%$

$5 \%$

$1 \%$

$1 \%$

$1 \%$

$1 \%$

$1 \%$

$1 \%$

Qty.

2

12

12

USECO 2003 B-1 terminals(Rx01,02,03 if needed)

Damping resistors

(Rx01,02,03 if needed)

Bufferfly P.C. card ejectors
6

6

12

12

6

6

6

6

6

6

6

6

6 
Table 2

Jumper Settings

\begin{tabular}{|l|c|c|c|c|}
\hline Gain & JPx01 & JPx02 & JPx03 & JPx04 \\
\hline $0 \mathrm{~dB}$ & & & & $X$ \\
\hline $20 \mathrm{~dB}$ & $\mathrm{X}$ & & & $X$ \\
\hline $40 \mathrm{~dB}$ & & $\mathrm{X}$ & & $X$ \\
\hline $60 \mathrm{~dB}$ & & & $X$ & $X$ \\
\hline $80 \mathrm{~dB}$ & & & $X$ & \\
\hline
\end{tabular}

$$
X=\text { jumper installed, blank }=\text { no jumper }
$$




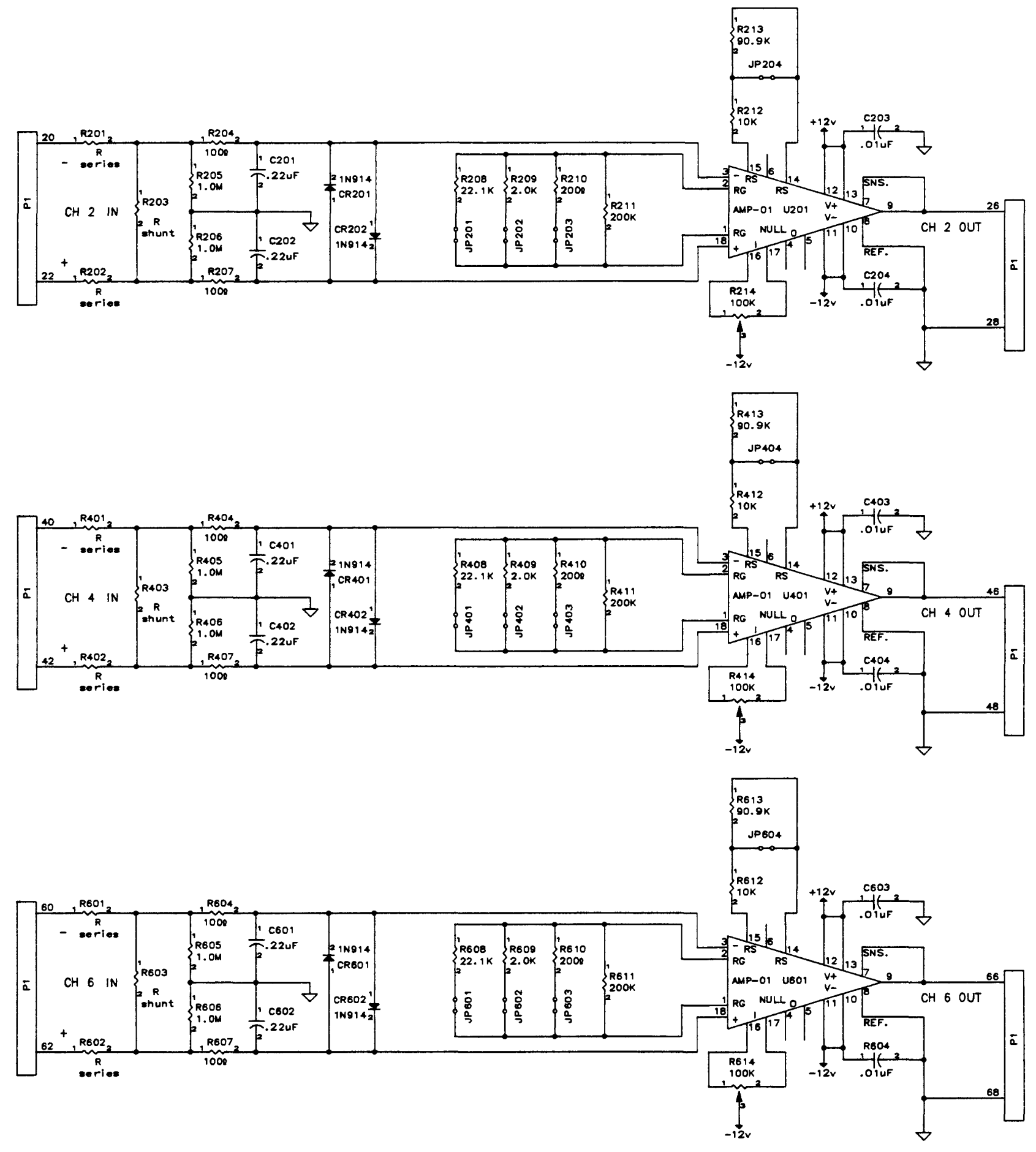




\title{
Appendix A
}

\author{
for \\ A Six-Channel Seismic Amplifier \\ Open-File Report \#90-346
}

\section{Contents:}

Five printed circuit board photographic films

Two printed circuit board fabrication drawings 


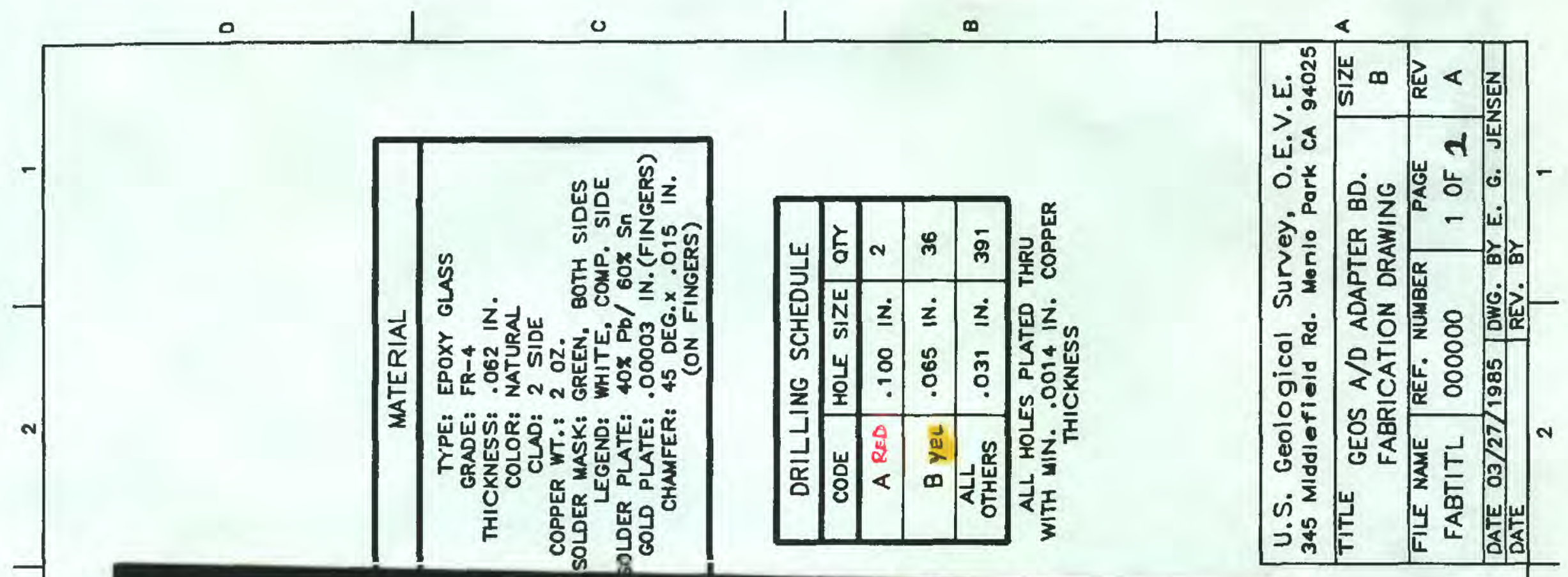

$\infty$ 


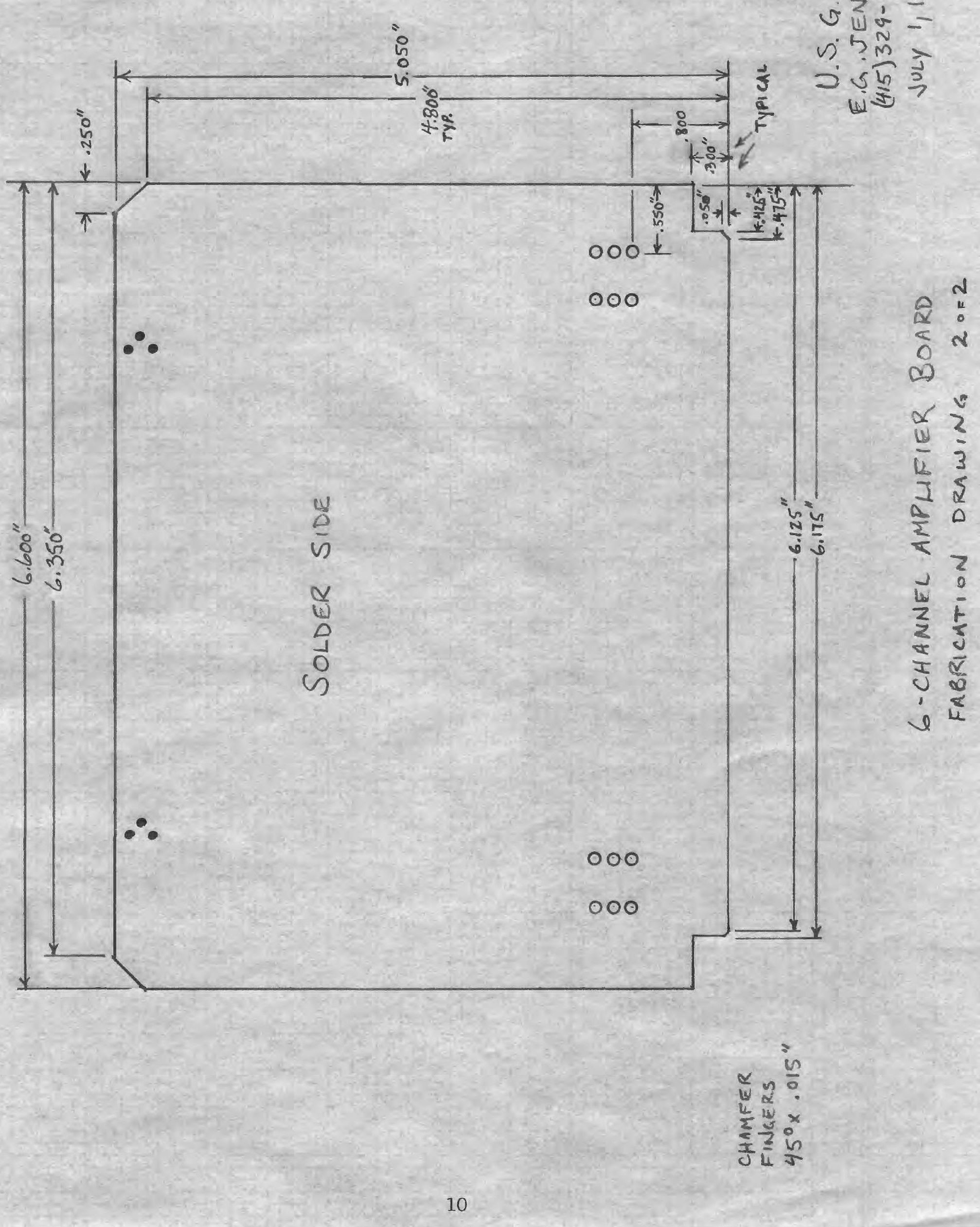

